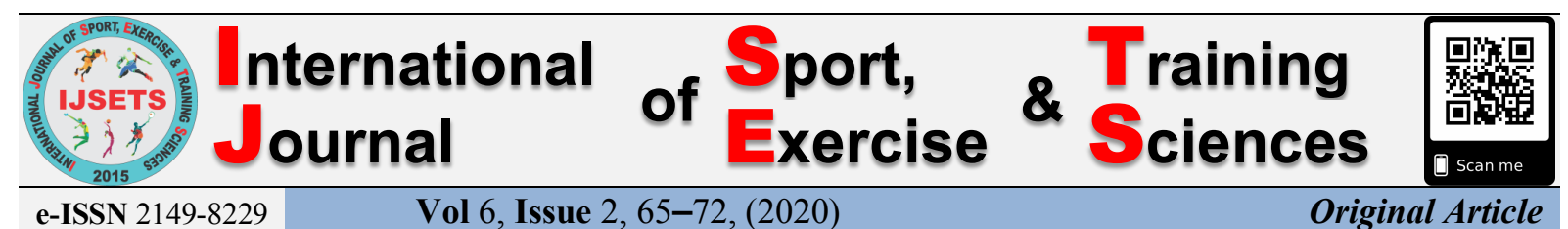

http://dergipark.gov.tr/useeabd

\title{
Kinematical variables analysis of shot-put activity in para athletics (Class F32/33) and their relationships with digital level achievement.
}

\author{
Guebli ABDELKADER ${ }^{1}$, Reguieg MADANI ${ }^{2}$, Sba BOUABDELLAH ${ }^{3}$
}

\begin{abstract}
Aim: The primary purpose of this part of was to Kinematical variables analysis of shot-put activity in Para-Athletics (Class F32/33) and their relationships with digital level achievement. Methods: International Paralympic athlete "Kerdjana Kamel" participated voluntarily in this study. He's the gold medalist and the record holder in this class F32/33 (Age: 37 years, Height: $1.76 \mathrm{~m}$, Weight: $82 \mathrm{~kg}$, Type of Impairment: cerebral palsy, origin of impairment: congenital, club: GSP Alger, Best Digital level: $12.24 \mathrm{~m}$ ). The analysis of the present study was doing with the software Kinovea software 0.8 .15 for the kinematical analysis, we used two cameras (AEE. $120 \mathrm{ips}, 1280 * 720,720 \mathrm{p}$ ) for record the Kinematic performance during the first and second phase (Start and Finish Pushing) in the Shot-Put. sites of this cameras (Cam; X0.5m, Y1.5m. Cam; X6m, Y5.5m). Shot-Put tries were applied for our sample (the international Paralympic athlete) in eight tries, we choose the best six tries for analysis. The data were analyzed in SPSS program, descriptive statistics (mean \pm Sd, Std.E) and Pearson test for the correlations between variables.

Results: As a result of the statistical analysis, there was a positive significant correlations of the Digital level with Distance of shot from the armrest $(0.04 *)$, and with The wrist Angle of the shooting hand $\left(0.015^{*}\right)$ in the first phase (start pushing), and in the second phase (finish pushing) there was a negative significant correlations of the Digital level with Pushing angle ($\left.0.013^{*}\right)$, and Positive significant correlations with Shot height $\left(0.006^{* *}\right)$.

Conclusion: Based on the kinetic Performance results analysis of Paralympic elite (the ShotPut Activity, Class 32/33) in practice; we confirm: 1) The increase in the variables values of Distance shot from the armrest, and the wrist Angle of the shooting hand in first phase of pushing (start) are affects the digital level achievement, Also the Shot height variable in the second phase of pushing, 2) The decrease in the value of Pushing angle variable in second phase of pushing (finish) is affect the digital level achievement.
\end{abstract}

\section{INTRODUCTION}

Biomechanics is the main field of objective research into the technical rules and methods of various kinetic skills (Guebli, Regiueg, et al., 2018). This is affected through precise measurements that are processed quantitatively by the laws of physics (R. Bartlett, 2007; Zerf Mohammed et al., 2015). There is no doubt that the objective study of any skill contributes to the development of the scientific foundations of the participant in terms of their ability to innovate and reach the best performance level possible (Elbadry et al., 2019). Biomechanical Knowledge is a "Must" for Coaching. All movements of Athletes are determined by the laws of mechanics. It is the first task of science (but only the first) to understand movements of athletes; therefore, it is an indispensable base for understand the basics of Performance kinetic in different activity and for coaching. In the throwing events the factors influencing the performance are classified into: 1 . the physical laws of the flight phases of the implement and; 2 . the biomechanical laws of the movement of the system 'thrower and implement' before release (SUGUMAR.C, 2012). Video analysis is a great system that films one's performance and reconstructs a model of one. Athletes can then compare one's technique on a good day and a bad day, athlete can compare one's technique with an expert (if one are not already), and much, much more (Franks \& Goodman, 1986).

Paralympic Games is a multi-sport event for athletes with physical, mental and sensorial disabilities. This includes mobility disabilities, amputees, visual disabilities and those with cerebral

\footnotetext{
The role and contributions of each authors as in the section of IJSETS Writing Rules "Criteria for Authorship" is reported that: 1. Author: Contributions to the conception or design of the paper, data collection, writing of the paper and final approval of the version to be published paper; 2. Author: Data collection, preparation of the paper according to rules of the journal, final approval of the version to be published paper; 3. Author: Statistical analysis, interpretation of the data and final approval of the version to be published paper.

${ }^{1}$ Corresponding Author: Laboratory APS, Society, Education and Health, Faculty of Physical Education and Sport, Hassiba Benbouali University, Chlef/Algeria, abdelkader85@windowslive.com. ORCID ID: 0000-0001-5314-4903.

${ }^{2}$ SMAH Laboratory, Faculty of Physical Education and Sport, Abdelhamid Ibn Badiss University, Mostaganem/Algeria, mad_eps@yahoo.fr ORCID ID: 00000002-8090-0257

${ }^{3}$ Laboratory APS, Society, Education and Health, Faculty of Physical Education and Sport, Hassiba Benbouali University, Chlef/Algeria, b.sba@univ-chlef.dz ORCID ID: 0000-0001-9733-6990
} 
palsy (Brittain, 2016). The Paralympic Games are held every four years, following the Olympic Games, and are governed by the International Paralympic Committee IPC (International Paralympic Committee 2018). The Paralympic Games is the highest obtainable level for all athletes. Evidence based classification in Paralympic Sport requires evidence for the impact of the underlying impairment on sport specific performance (Webborn, 2009). During Rio 2016 Paralympic Games, 4350 athletes from more than 160 countries participated in these games for 528 males from different sports (Van Biesen et al., 2018). In para athletics open to athletes in various disability groups, based on a functional classification system, which is coordinated by world para athletics sports technical committee (van Dijk et al., 2017). Algeria achieved new Gold medals in the male competitions for elite throwers with impairment of cerebral palsy (Class F32/33). The level of competition was of high quality, where Performing well in shot-put consists of simply throwing the shot as far as possible (Landolsi et al., 2018).

Kinematic analyses of the throwing techniques of elite stationary shot-putters are commonly conducted in routine observations and sport research (Ariel et al., 2005). Some of these analyses focused on parameters underlining either the sequence of actions taken by the athlete leading to the release of the shot (e.g. spatial and temporal characteristics of backward and forward thrust, range of motion, linear and angular momentum of each segment) or the shot's trajectory at the instant of release (e.g. position, speed and angle of shot) (John W. Chow et al., 2000; O'Riordan \& Frossard, 2006). To the best of our knowledge, most research has focused on biomechanical variables of the para-athletics and studied the effects, comparative and correlation of kinetic and kinematics variables with digital level (Guebli, Bessenouci, et al., 2018), in athletics disciplines such as the Shot-Put throw (Abdelkader et al., 2018a; Błażkiewicz et al., 2019; Gilberto, n.d.; Hubbard et al., 2001; Landolsi et al., 2018; Lee et al., 2015; Willwacher et al., 2011), Discus Throw (Abdelkader et al., 2018a; R. M. Bartlett, 1992; Błażkiewicz et al., 2019; J. W. Chow \& Mindock, 1999; Delgado, 2012; Hay \& Yu, 1995; Leigh et al., 2010; Maroński, 1991; Shestakov, 2005). Some of these analyses focused on parameters underlining either the sequence of actions taken by the athlete leading to the release of the throw (e.g. spatial and temporal characteristics of backward and forward thrust, range of motion, linear and angular momentum of each segment) or the throw's trajectory at the instant of release (e.g. position, speed and angle of throw) (L. Frossard et al., 2007).

These studies contributed to improvement of training programs of stationary throwers as they provided coaches and athletes with a better understanding of throwing technique as well as strength and fitness requirements (O'Riordan \& Frossard, 2006), along with the long-term development of very complex skills, and the abil-ity to perform these complex and precisely timed movements at high velocity in a confined space (i.e. technique) (Marcos Gutiérrez-Davila et al., 2009; SUGUMAR.C, 2012), Where G. Davila reported that the shot-put technique is individual; each thrower uses his or her own individual temporal sequence and rhythm. Apart from the body composition and strength of the thrower, also the degree of automation of the individual temporal sequence determines the optimal individual technique (John W. Chow et al., 2000; Marcos Gutiérrez-Davila et al., 2009). however, it remains currently unknown whether the observed differences in performance are due to: intrinsic factors of the throwers (e.g. body composition, strength), external factors (e.g. training volume, quality of the coaches), their underlying cognitive impairment, or a combination of multiple factors (L. Frossard et al., 2007) or the characteristics of kinetic performance in Shot Put Activity in Paralympic Athletcs.

Thus, the present study aimed at Continue the work initiated by Guebli et al, 2017 by reporting the parameters of the shot's trajectory for male gold medal during world-class events, and analyzing the kinetic performance in different Para-athletics class in this activity. Also, to provide the magnitude of differences in these parameters across classes and genders. Therefore, the primary purpose of this part of was to Kinematical variables analysis of shot-put activity in para-athletics (Class F32/33) and their relationships with the digital level achievement.

\section{METHOD}

\section{Participants}

International paralympic athlet "Kerdjana Kamel" participated voluntarily in this study. The participant is the gold medalist and the record holder in this class F32/33. Kerdjana Kamel (Age: 37 years, Height: 
$1.76 \mathrm{~m}$, Weight: $82 \mathrm{~kg}$, Type of Impairment: celebral pallsy, origin of impairment: congenital, club: GSP Alger, Best Digital level: $12.24 \mathrm{~m}$ ).

Ethics Committee approval of this study was obtained from Laboratory APS, Society, Education and Health, Faculty of Physical Education and Sports, Hassiba Benboualy University of Chlef, doctorat project Committee (2016/ biomechanics of Physical Activities and Sport).

Research Design: For the purposes of analysis, we have calculated the distance of the Shot-Put in twodimensional. The analysis of the present study was with the software Kinovea, the capture and measured distance of each phase of Shot-Put as Fig.1. Sites of the two cameras that depicting the distance Shotput These cameras (AEE MagicCam, $170^{\circ}$ view, MOV Format Video, 720p Video Resolution, 120 ips NTFS, Screen Resolution 1280*720 16:9).

Were placed at distances of X0.5 m and X6 m from the midline of shot-Put circle, with their optical axes at right angles to this line. The first camera was placed Y1.5 $\mathrm{m}$ forward (or on the circle side) from the axis of the circle and was used to record the Kinematic performance during the first and second phase (Start and Finish Pushing) of the Shot-Put.

The second camera was placed Y5.5 $\mathrm{m}$ forward of the front edge of the board and was used to record performance during the second phase in Shot-Put. To measure the real distance, a series of markers was placed in carefully measured locations along the inside. These markers served as reference measurement. Shot-Put tries were applied for our

Fig 1 . The method chosen to Capture Video of the variables in Shot-Put Performance.

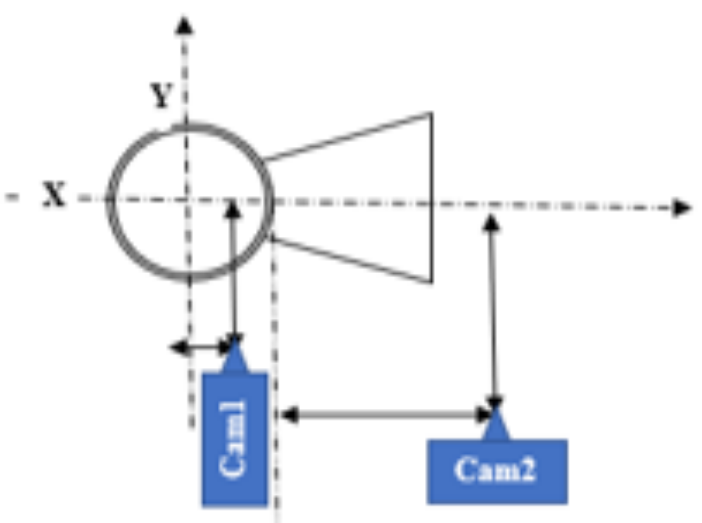
sample (the international paralympic athlete) in eigh tries, we choos the best six tries for analysis.

Kinematic Variables: Based in the similar studies, we choose the kinematic variables for analysing the performance kinematic of athlete in shot-put activity class F32/33 in two phase, the first phase of start pushing (variables; The number of swings, Standby time, Time of push, Distance of shot from the armrest, Trunk angle, Cubitus Angle of the shooting hand, Shoulder angle of the shooting hand, The wrist Angle of the shooting hand, Cubitus Angle of the Support hand, Shoulder angle of the Support hand, Distance of shot from the neck), and in the second phase of finish pushing (variables; Digital level, Trunk angle, Cubitus Angle of the shooting hand, Shoulder angle of the shooting hand, The wrist Angle of the shooting hand, Pushing angle, Shot height, Max height of shot, Time of Throwing, Total Performance Time).

We used kinovea softwore 0.8 .15 for the kinematical analysis, it's a video player for sport analysis. It provides a set of tools to capture, slow down, study, compare, annotate and measure technical performances.

\section{Data Collection}

Our cameras were attached to our laptops to record directly into folders prepare in advance for each attempt chosen for analysis. The distances of the analysis's tests are shown in Table 1 for the athlete of Algerian Paralympic elite. With the software Kinovea, the films obtained for each try were phase analysis for each variable and try.

\section{Statistical analysis}

The data analysis procedures used in this study consisted of the computation of the means, standard deviations (SD), standard deviation Error (Std.E) as descriptive statistics, and the Pearson test for the correlations between all variables identified in based of similar studies. Statistical results were analyzed at $(\mathrm{p}<0.05)$ and $(\mathrm{p}<0.01)$ significance levels.

We used SPSS (SPSS for Windows, version 22.0, SPSS Inc. Chicago, Illinois, USA) statistical program for that statistical analysis of the data obtained. 


\section{RESULTS}

Table 1. Description Results of the Algerian world Champion of Shot-Put Class F32/33 "Kerdjana Kamel" in the kinematic analysis of his Performance.

\begin{tabular}{|c|c|c|c|c|c|c|}
\hline Variables & Mean \pm Sd & $\begin{array}{l}\text { Std. E } \\
\text { Stage I }\end{array}$ & Min/Max & \multicolumn{3}{|c|}{ Stage П } \\
\hline & $10.423 \pm 0.015$ & 0.006 & $09.40 / 10.44$ & $10.423 \pm 0.015$ & 0.006 & $09.40 / 10.44$ \\
\hline swings & $3.166 \pm 0.408$ & 0.166 & $3.00 / 4.00$ & & & \\
\hline (s) & $2.285 \pm 0.015$ & 0.006 & $2.27 / 2.31$ & & & \\
\hline (s) & $0.305 \pm 0.005$ & 0.002 & $0.30 / 0.31$ & & - & \\
\hline $\operatorname{arest}(\mathrm{cm})$ & $51.253 \pm 0.017$ & 0.007 & $51.23 / 51.28$ & & & \\
\hline & $62.333 \pm 0.816$ & 0.333 & $61.00 / 63.00$ & $86.166 \pm 0.408$ & 0.166 & $86.00 / 87.00$ \\
\hline of the shooting hand $\left({ }^{\circ}\right)$ & $16.333 \pm 0.816$ & 0.333 & $15.00 / 17.00$ & $154.666 \pm 0.816$ & 0.333 & $154.00 / 156.00$ \\
\hline of the shooting hand $\left({ }^{\circ}\right)$ & $24.000 \pm 0.894$ & 0.365 & $23.00 / 25.00$ & $160.833 \pm 1.834$ & 0.749 & $159.00 / 163.00$ \\
\hline of the shooting hand( $\left(^{\circ}\right)$ & $108.166 \pm 1.329$ & 0.542 & $106.00 / 109.00$ & $155.166 \pm 0.983$ & 0.401 & $154.00 / 156.00$ \\
\hline Support hand $\left(^{\circ}\right)$ & $116.500 \pm 1.048$ & 0.428 & $115.00 / 118.00$ & & & \\
\hline e Support hand $\left({ }^{\circ}\right)$ & $56.000 \pm 2.00$ & 0.816 & $54.00 / 59.000$ & & ---- & \\
\hline t from the neck $(\mathrm{cm})$ & $12.096 \pm 0.030$ & 0.012 & $12.05 / 12.130$ & & & \\
\hline$\left({ }^{\circ}\right)$ & & & & $50.500 \pm 1.048$ & 0.428 & $49.00 / 52.00$ \\
\hline & & & & $202.785 \pm .815$ & 0.333 & $201.12 / 203.16$ \\
\hline $\operatorname{hot}(\mathrm{cm})$ & & ---- & & $399.468 \pm 1.480$ & 0.604 & $397.66 / 401.26$ \\
\hline wing (s) & & & & $1.658 \pm .018$ & 0.007 & $1.64 / 1.68$ \\
\hline Iance Time (s) & & & & $4.248 \pm 0.027$ & 0.011 & $4.22 / 4.28$ \\
\hline
\end{tabular}

Table 1 shows the description results of performance kinematic Analysis for our sample "Kerajaan Kamel" (the Algerian world Champion, Class F32/33) in Shot-Put activity during the first and second stage of performance (start \& finish pushing), the results explaine the values of mean $\pm \mathrm{Sd}$, Std.Error, Minimal and maximal Values of variables.

Table 2. The connectivity relationships between variables in order to study in stages of performance (I and ПI).

\begin{tabular}{|c|c|c|c|c|c|}
\hline \multicolumn{2}{|c|}{$\begin{array}{c}\text { The Variables correlated } \\
\text { Stage I }\end{array}$} & Sig. $p$ & \multicolumn{2}{|c|}{$\begin{array}{c}\text { The Variables correlated } \\
\text { Stage } \Pi\end{array}$} & Sig. $p$ \\
\hline & $\begin{array}{l}\text { Distance of shot from } \\
\text { the armrest }\end{array}$ & $\begin{array}{c}0.832^{*} \\
0.040\end{array}$ & & Pushing angle & $\begin{array}{c}-0.907^{*} \\
0.013\end{array}$ \\
\hline igital le & $\begin{array}{l}\text { The wrist Angle of } \\
\text { the shooting hand }\end{array}$ & $\begin{array}{c}0.898^{*} \\
0.015\end{array}$ & 1gital & Shot & $\begin{array}{c}0.935^{* *} \\
0.006\end{array}$ \\
\hline Time of push & $\begin{array}{l}\text { of of shot from } \\
\text { irest }\end{array}$ & $\begin{array}{c}-0.891^{*} \\
0.017\end{array}$ & Shot height & Pushing a & $\begin{array}{l}-0.813^{*} \\
0.049\end{array}$ \\
\hline & ngle of the & $\begin{array}{c}-0.905^{*} \\
0.013\end{array}$ & Max height of shot & $\begin{array}{l}\text { e of the } \\
d\end{array}$ & $\begin{array}{l}0.845^{*} \\
0.034\end{array}$ \\
\hline $\begin{array}{l}\text { Shoulder angle of } \\
\text { the Support hand }\end{array}$ & $\begin{array}{l}\text { Distance of shot from } \\
\text { the armrest }\end{array}$ & $\begin{array}{c}0.985^{* *} \\
0.000\end{array}$ & $\begin{array}{l}\text { The wrist Ang } \\
\text { the shooting he }\end{array}$ & $\begin{array}{l}\text { le of the } \\
\text { d }\end{array}$ & $\begin{array}{c}0.953^{* *} \\
0.003\end{array}$ \\
\hline $\begin{array}{l}\text { Distance of shot } \\
\text { from the neck }\end{array}$ & Trunk angle & $\begin{array}{c}-0.820^{*} \\
0.046\end{array}$ & $\begin{array}{l}\text { Total Performance } \\
\text { Time }\end{array}$ & Time & $\begin{array}{c}0.818^{*} \\
0.047\end{array}$ \\
\hline \multicolumn{6}{|c|}{ The Variables correlated between Stage I \& Stage II } \\
\hline & Time of push & $\begin{array}{r}0.9 \\
.01\end{array}$ & & $\begin{array}{l}\text { Cubit } \\
\text { shoot }\end{array}$ & $\begin{array}{c}-0.850 * \\
0.032\end{array}$ \\
\hline Pushing angle & $\begin{array}{l}\text { e of shot from } \\
\text { rest }\end{array}$ & $\begin{array}{c}-0.985^{* *} \\
.0000\end{array}$ & $\begin{array}{l}\text { Cub } \\
\text { shoo }\end{array}$ & $\begin{array}{l}\text { gle of the } \\
\text { id I }\end{array}$ & $\begin{array}{c}0.839^{*} \\
0.037\end{array}$ \\
\hline & ngle of the & $-0.955^{* *}$ & & le of the & $0.953 * *$ \\
\hline & & & & & 0.003 \\
\hline Shot height & $\begin{array}{l}\text { The wrist angle of } \\
\text { the shooting hand }\end{array}$ & $\begin{array}{c}0.826^{*} \\
0.043\end{array}$ & Time of Throwing & Standby time & $\begin{array}{c}0.818^{*} \\
0.047\end{array}$ \\
\hline $\begin{array}{l}\text { The wrist Angle of } \\
\text { the shooting hand } \Pi\end{array}$ & $\begin{array}{l}\text { Shoulder angle of the } \\
\text { shooting hand I }\end{array}$ & $\begin{array}{c}0.904^{*} \\
0.013\end{array}$ & Max height of shot & $\begin{array}{l}\text { Cubitus angle of the } \\
\text { shooting hand I }\end{array}$ & $\begin{array}{c}-0.939 * * \\
0.005\end{array}$ \\
\hline
\end{tabular}

$(p<0.05)^{*}$ Correlation is significant at the 0.05 level.

$(p<0.01)^{* *}$ Correlation is significant at the 0.01 level (1-tailed). 
Table 2; shows the correlation results between kinematic variables for our sample in the first stage of Shot-put (start pushing), in the second stage (finish pushing), also between kinematic variables of first and second stage in shot-put. The significant correlation was observed at the $0.01 \& 0.05$ level (1tailed) and degrees of freedom (n-1) between the values of kinetic performance in the first stage (start pushing), the correlations are positive significant in; the Digital level with Distance of shot from the armrest $\left(0.040^{*}\right)$, and with the wrist Angle of the shooting hand $\left(0.015^{*}\right)$ at the 0.05 level. Also, between the Shoulder angle of the Support hand with Distance of shot from the armrest $\left(0.000^{* *}\right)$ at the 0.01 level. The correlations are negative significant in; Time of push with Distance of shot from the armrest $\left(-0.017^{*}\right)$, and with Shoulder angle of the Support hand $\left(-0.013^{*}\right)$, also between Distance of shot from the neck and Trunk angle $\left(-0.046^{*}\right)$ at the 0.05 level.

The significant correlation was observed at the $0.01 \& 0.05$ level (1-tailed) and degrees of freedom (n-1) between the values of kinetic performance in the second stage (finish pushing), the correlations are positive significant in; Max height of shot with the Cubitus angle of the shooting hand $\left(0.034^{*}\right)$, and Total Performance Time with the Time of Throwing $\left(0.047^{*}\right)$ at the 0.05 level. Also, between the Digital level with Shot height $\left(0.006^{* *}\right)$, and between the wrist Angle of the shooting hand with the Shoulder angle of the shooting hand $\left(0.003^{* *}\right)$ at the 0.01 level. The correlations are negative significant in the Digital level with Pushing angle $\left(-0.013^{*}\right)$ at the 0.05 level, and Positive significant with Shot height $\left(0.006^{* *}\right)$ at the 0.01 level.

The significant correlation was observed at the $0.01 \& 0.05$ level (1-tailed) and degrees of freedom (n-1) between the values of kinetic performance in the first and second stage (start and finish pushing), the correlations are positive significant in; Pushing angle with Time of push $\left(0.013^{*}\right)$, and Shot height with The wrist angle of the shooting hand $\left(0.043^{*}\right)$, and The wrist Angle of the shooting hand $\Pi$ with Shoulder angle of the shooting hand I $\left(0.013^{*}\right)$, and the Cubitus Angle of the shooting hand $\Pi$ with Shoulder angle of the shooting hand I $\left(0.037^{*}\right)$, and the Time of Throwing with Standby time $\left(0.047^{*}\right)$ at the 0.05 level, and between the Cubitus Angle of the shooting hand $\Pi$ with Cubitus Angle of the Support hand $(0.003 * *)$ at the 0.01 level. The correlations are negative significant in; Cubitus Angle of the shooting hand $\Pi$ with Cubitus Angle of the shooting hand I $\left(-0.032^{*}\right)$ at the 0.05 level, also, between the Max height of shot with Cubitus angle of the shooting hand I (-0.005**), and Pushing angle with Distance of shot from the armrest $\left(-0.000^{* *}\right)$ and with Shoulder angle of the Support hand $\left(-0.003^{* *}\right)$ at the 0.01 level.

\section{DISCUSSION}

The goal of this study was to the Kinematical variables' analysis of shot-put activity in Para-Athletics (Class F32/33) and their relationships with digital level achievement. The results indicated that the correlation values of Variables; Distance of shot from the armrest, the wrist Angle of the shooting hand (start pushing), and the Shot height, pushing angle (finish pushing) were significant with the digital level achievement. from that, also we can see the significant correlation values of Variables; Distance of shot from the armrest with the Shoulder angle of the Support hand, and the Pushing angle. also, the wrist Angle of the shooting hand with the Shoulder angle of the shooting hand, and Shot height. also, the Pushing angle with Shot height with Time of push, and Distance of shot from the armrest, and with the Shoulder angle of the Support hand. These kinematic variables in the performance of our sample, were important for effective and supportive for basics variables correlated to digital level achievement.

According to Biomechanical \& Performance researches, a most basic kinematic variables effective in shot putting techniques of disability male athletes, with a result in reduction of the acceleration path of the shot resulting in a lower speed of the shot at release (Abdelkader et al., 2018b). the digital level and pushing angle are inversely related. As one parameter increases, the other decreases. Pushing angle can be manipulated depending on the throwers strength and anthropometrics (Cooper \& Luigi, 2014). Projectiles obey constant acceleration, making them easier to describe and understand (Galileo's equations). Three factors deter -mine trajectory, including horizontal displacement, of a projectile: speed of release, angle of release, height of release (Maroński, 1991). The goal is to determine the pushing angle that optimizes the total distance for the release velocity attained for the thrower. For the shot put, the optimum angle of release is between $31^{\circ}$ and $36^{\circ}$ (SUGUMAR.C, 2012), Positive height of release, optimal angle should be slightly lower than $45^{\circ}$. Theoretically optimal angle is about $40-41^{\circ}$. Skilled 
shot-putters use angles of $35-37^{\circ}$ (Judge et al., 2016). The mathematically calculated optimal release angle $\alpha$ opt ranges from $40^{\circ}$ to $43^{\circ}$ and is calculated by the following formula (Milan coh et al., 2008):

$$
\alpha_{\mathrm{opt}}=\frac{1}{2} \arccos \left(\frac{1}{1+\frac{\mathrm{v}_{\mathrm{R}}^{2}}{\mathrm{gh}_{\mathrm{R}}}}\right)
$$

but in the present study indicates that the shot-putter has achieve distance of $10.423 \pm 0.015$ meters. Shotputter use angles of Push are $49^{\circ}-52^{\circ}$. All athletes have their own specific optimum Pushing angle because of individual differences in the rate of force generation and apply and the Disability classification (Keogh \& Burkett, 2013). where, the study results may depend upon the factors related to shot put performance, Lowest and highest shot-put performance depends upon the angle of release. To achieve good performances, it is not necessary to throw at very close to the optimum release angle. Throwing with a high release speed is more important to performance than throwing at the optimum release angle (L. A. Frossard et al., 2005; Perrin et al., 2000).

As expected, these results confirm the findings of previous studies focusing two predominant factors, The velocity and angle to the performance of gold medalists (Abdelkader et al., 2018b). The lack of strong relationship with the position at release might be explained by the difference in Shot height was since all the throwing frames have the same height of $75 \mathrm{~cm}$, corresponding to the maximum height allowed by the IPC's rule (L. Frossard et al., 2007). The main mechanisms explained for that performance analysis are the Technique acquisition might be one major factor which is restricted by a cerebral palsy disability (Kohe \& Peters, 2016).

However, it is likely that the performance relied more importantly on the throwing technique and functional outcome as they are both directly related to velocity and angle of release. Shot-putting requires great explosive strength, together with the ability to perform precisely timed movements in a confined space(Landolsi et al., 2018). The athlete's objective is to project the shot as far as possible, but competition regulations restrict the technique that may be used. The shot must be thrown from the shoulder using one hand and it must be held near to the chin throughout any preliminary movements (Błażkiewicz et al., 2016).

In the end, sport scientists, coaches, athletes and classifiers can only rely partially on data provided in the literature for a sound understanding of the current performance of medalist stationary shot-putters (L. A. Frossard et al., 2005). As pointed out by Chow 2000, "More quantitative data, especially those collected during major competitions, are needed for the development of a data base on performance characteristics" (John W. Chow et al., 2000). Anyone with a serious interest in the performance of toplevel athletes should appreciate the importance of the smallest worthwhile change in performance, the change that makes a meaningful difference to an athlete's chances of winning. Also, knowledge of this change is needed when assessing athletes with a performance test either to make decisions about meaningful changes in an individual or to re-search strategies that might affect performance.

\section{CONCLUSION}

As a results of kinetic Performance analysis of Paralympic elite (the Shot-Put Activity, Class 32/33) in practice; we confirm: 1) The increase in the variables values of Distance shot from the armrest, and the wrist Angle of the shooting hand in first phase of pushing (start) are affects the digital level achievement, Also the Shot height variable in the second phase of pushing, 2) The decrease in the value of Pushing angle variable in second phase of pushing (finish) is affect the digital level achievement.

\section{PRACTICAL APPLICATION}

The kinematical analysis of performance is very importenet for achinement the the digital level, for that, we need to focus on applying biomechanical principles to during kinetic performance, Also Ensure that the required mechanical position is taken at every stage of performance and in line with the kinetic 
performance requirements. Especially for the Paralympic athletes due to their physical and kinetical characteristics, depending on the nature and classification of their disability.

\section{REFERENCES}

Abdelkader, G., Madani, R., Adel, B., \& Bouabdellah, S. (2018a). Sporting events among the disabled between excellence and ideal in motor performance. International Journal of Physical Education, Fitness and Sports, 7(3), 66-71. https://doi.org/10.26524/ijpefs1837

Abdelkader, G., Madani, R., Adel, B., \& Bouabdellah, S. (2018b). Sporting events among the disabled between excellence and ideal in motor performance. International Journal of Physical Education, Fitness and Sports, 7(3), 66-71. https://doi.org/10.26524/ijpefs1837

Ariel, G., Penny, A., Probe, J., \& Finch, A. (2005). Biomechanical analysis of the shot.put event at the 2004 Athens Olympic games. 4.

Bartlett, R. (2007). Introduction to Sports Biomechanics, (2nd ed.).

Bartlett, R. M. (1992). The biomechanics of the discus throw: A review. Journal of Sports Sciences, 10(5), 467-510. https://doi.org/10.1080/02640419208729944

Błażkiewicz, M., Łysoń, B., Chmielewski, A., \& Wit, A. (2016). Transfer of mechanical energy during the shot put. Journal of Human Kinetics, 52, 139-146. https://doi.org/10.1515/hukin2016-0001

Błażkiewicz, M., Łysoń, B., \& Wit, A. (2019). Mechanical energy flows between body segments in ballistic track-and-field movements (shot put, discus, javelin) as a performance evaluation method. Acta of Bioengineering and Biomechanics, 21(1), 31-36.

Brittain, I. (2016). The Paralympic Games Explained (Second Edition). Routledge.

Chow, J. W., \& Mindock, L. A. (1999). Discus throwing performances and medical classification of wheelchair athletes. Medicine and Science in Sports and Exercise, 31(9), 1272-1279. https://doi.org/10.1097/00005768-199909000-00007

Chow, John W., Chae, W.-S., \& Crawford, M. J. (2000). Kinematic analysis of shot-putting performed by wheelchair athletes of different medical classes. Journal of Sports Sciences, 18(5), 321-330. https://doi.org/10.1080/026404100402386

Cooper, R. A., \& Luigi, A. J. D. (2014). Adaptive Sports Technology and Biomechanics: Wheelchairs. $P M \& R, 6$, S31-S39. https://doi.org/10.1016/j.pmrj.2014.05.020

Delgado, C. (2012). The Biomechanical Analysis of the Discus Throw: Stages and Suggested Training Techniques. The International Journal of Sport and Society, 2(4), 1-10. https://doi.org/10.18848/2152-7857/CGP/v02i04/53881

Elbadry, N., Hamza, A., Pietraszewski, P., Alexe, D. I., \& Lupu, G. (2019). Effect of the French Contrast Method on Explosive Strength and Kinematic Parameters of the Triple Jump Among Female College Athletes. Journal of Human Kinetics, 69(1), 225-230. https://doi.org/10.2478/hukin-2019-0047

Franks, I. M., \& Goodman, D. (1986). A systematic approach to analysing sports performance. Journal of Sports Sciences, 4(1), 49-59. https://doi.org/10.1080/02640418608732098

Frossard, L. A., O'Riordan, A., \& Goodman, S. (2005). Applied biomechanics for evidencebased training of Australian elite seated throwers. International Council of Sport Science and Physical Education Perspectives Series. https://eprints.qut.edu.au/2713/

Frossard, L., Smeathers, J., O'Riordan, A., \& Goodman, S. (2007). Shot Trajectory Parameters in Gold Medal Stationary Shot-Putters during World-Class Competition. Adapted Physical Activity Quarterly, 24(4), 317-331. https://doi.org/10.1123/apaq.24.4.317

Gilberto, M. F. (n.d.). Shot Put Regulations Changes and Implications in Physically Challenged Athletes Performance. 
Guebli, A., Bessenouci, H. A. I., \& Regiueg, M. (2018). The Compounds of Some Variables Kinematics in the Phases of Triple Jump and Their Relationships with the Finale ResultsAn analytical study of the elements of the Algerian elite team-. journal of physical activity and sport, society, education and health, 1(1), 25-31. https://www.asjp.cerist.dz/en/article/67719

Guebli, A., Regiueg, M., \& Sbaa, B. (2018). The Value of Dynamic Priorities in Motor Learning between Some Basic Skills in Beginner's Basketball, U14 Years. Sport Management and Sport Marketing, 12, 1. https://doi.org/dai.waset.org/1307-6892/92495

Hay, J. G., \& Yu, B. (1995). Critical characteristics of technique in throwing the discus. Journal of Sports Sciences, 13(2), 125-140. https://doi.org/10.1080/02640419508732220

Hubbard, M., de Mestre, N. J., \& Scott, J. (2001). Dependence of release variables in the shot put. Journal of Biomechanics, 34(4), 449-456. https://doi.org/10.1016/s00219290(00)00228-1

Judge, L. W., Bellar, D. M., Craig, B. W., Gilreath, E. L., Cappos, S. A., \& Thrasher, A. B. (2016). Influence of Postactivation Potentiation on Shot Put Performance of Collegiate Throwers. Journal of Strength and Conditioning Research, 30(2), 438-445. https://doi.org/10.1097/JSC.0000000000000202

Keogh, J., \& Burkett, B. (2013, December 4). Kinematics of shot-put, discus and javelin throwing in Paralympic athletes. Routledge Handbook of Ergonomics in Sport and Exercise; Routledge. https://doi.org/10.4324/9780203123355-61

Kohe, G. Z., \& Peters, D. M. (2016). High Performance Disability Sport Coaching. Taylor \& Francis.

Landolsi, M., Labiadh, L., Zarrouk, F., Maaref, K., Ghannouchi, S., Tabka, Z., \& Lacouture, P. (2018). Kinematic analysis of the shot-put: A method of assessing the mechanical work of the hand action force. European Journal of Sport Science, 18(9), 1208-1216. https://doi.org/10.1080/17461391.2018.1478449

Lee, S., Davis, R., Judge, L. W., Kwon, Y.-H., Han, K., Kim, J., Kim, J., \& Kim, J. (2015). Gender-Based Correlation Profiles Among the Release Factors and Distance Thrown in Paralympic Seated Shot Put. Adapted Physical Activity Quarterly, 32(4), 318-330. https://doi.org/10.1123/APAQ.2014-0148

Leigh, S., Liu, H., Hubbard, M., \& Yu, B. (2010). Individualized optimal release angles in discus throwing. Journal of Biomechanics, 43(3), 540-545. https://doi.org/10.1016/j.jbiomech.2009.09.037

Marcos Gutiérrez-Davila, Javier Rojas, José Campos, Javier Gámez, \& Alberto Encarnación. (2009). Biomechanical analysis of the shot put at the 12th IAAF World Indoor Championships| News. https://www.worldathletics.org/news/news/biomechanical-analysisof-the-shot-put-at-the-1

Maroński, R. (1991). Optimal distance from the implement to the axis of rotation in hammer and discus throws. Journal of Biomechanics, 24(11), 999-1005. https://doi.org/10.1016/0021-9290(91)90017-h

Milan coh, Stanko stuhec, \& Matej Supej. (2008). Comparative biomechanical analysis of the rotational shot put technique | Matej Supej et Stanko Stuhec-Academia.edu. 32(1), 249256.

O'Riordan, A., \& Frossard, L. A. (2006). Seated Shot Put - What's it all about? Modern Athlete and Coach, 44(2), 2-8. 
Perrin, P., Perrot, C., Deviterne, D., Ragaru, B., \& Kingma, H. (2000). Dizziness in discus throwers is related to motion sickness generated while spinning. Acta Oto-Laryngologica, 120(3), 390-395. https://doi.org/10.1080/000164800750000621

Shestakov, M. P. (2005). Modelling of technical training of discus throwers in the period of significant changes of their mass-inertia characteristics. Journal of Physiological Anthropology and Applied Human Science, 24(4), 367-370. https://doi.org/10.2114/jpa.24.367

Sugumar, C. (2012). A Biomechanical Analysis of the Shot Put Performance. Global Journal for Research Analysis, 3(5), 118-119. https://doi.org/10.15373/22778160/MAY2014/44

Van Biesen, D., McCulloch, K., \& Vanlandewijck, Y. C. (2018). Comparison of shot-put release parameters and consistency in performance between elite throwers with and without intellectual impairment. International Journal of Sports Science \& Coaching, 13(1), 86-94. https://doi.org/10.1177/1747954117707483

van Dijk, A., Dad’ová, K., \& Martínková, I. (2017). Intellectual disability sport and Paralympic classification. $\quad A U C \quad$ Kinanthropologica, 53(1), 21-34. https://doi.org/10.14712/23366052.2017.2

Webborn, A. D. J. (2009). Paralympic Sports. https://doi.org/10.1002/9781444316872.ch30

Willwacher, S., Potthast, W., \& Müller, R. (2011). Shot Put Kinematics Of World Class Athletes With An Intellectual Disability. 4.

Zerf Mohammed, Mokkedes Moulay Idriss, Bengoua Ali, Bendahmane Med Nasreddin, \& Guebli Abd-el-Kader. (2015). The Impact of the Techniques and Tactics Appropriate by the Athletes in Phase Triple Jump and Their Relationships with the Finale Results. Journal of Sports Science, 3(4). https://doi.org/10.17265/2332-7839/2015.04.004

\section{CITATION OF THIS ARTICLE}

Abdelkader, G., \& Madani, R. \& Bouabdellah, S. (2020) Kinematical variables analysis of shot-put activity in para athletics (class F32/33) and their relationships with digital level achievement. International Journal of Sport, Exercise \& Training Sciences-IJSETS, 6(2), 65-72. DOI: 10.18826/useeabd.709944 